\title{
Construção dos itens da Escala de Autoeficácia para Escolha Profissional
}

\author{
Rodolfo Augusto Matteo Ambiell - Universidade São Francisco, Itatiba, Brasil \\ Ana Paula Porto Noronha - Universidade São Francisco, Itatiba, Brasil
}

\begin{abstract}
Resumo
Esse trabalho relata a construção dos itens da Escala de Autoeficácia para Escolha Profissional (EAE-EP). Na primeira etapa procedeu-se a uma busca em base de dados internacional para se levantar a produção a respeito do tema. Na segunda, procedeu-se à aplicação de um instrumento aberto, em 149 pessoas de diferentes situações educacionais e ocupacionais. Realizou-se análise de conteúdo nas respostas, agrupando-as em quatro categorias, que foram analisadas por juízes. Por fim, a terceira etapa envolveu a aplicação-piloto da versão inicial em estudantes do ensino médio para avaliar a clareza das instruções e redação dos itens. Os resultados não indicaram necessidade de mudanças significativas na estrutura da escala, que em estudos futuros poderá ter suas propriedades psicométricas testadas.

Palavras-chave: Escolha profissional, Autoeficácia, Orientação profissional, Avaliação psicológica, Testes psicológicos.
\end{abstract}

\section{Construction of the Professional Choice Self-Efficacy Scale's items}

\begin{abstract}
This study aimed to report the construction of the items for the Professional Choice Self-efficacy Scale (EAE-EP). In the first step a search in an international database was carried out to raise the production on the subject. In the second, it was proceeded to the implementation of an open-answer instrument in 149 subjects of different educational and occupational situations. Content analysis of the answers was carried out, grouping them into four categories, which were reviewed by judges. Finally, the third step involved the pilot application of the original version in high school students to evaluate the clarity of the instructions and wording of items. The results indicated no need for changes in the structure of the scale, that in future studies may have tested its psychometric properties.

Keywords: Professional choice, Self-efficacy, Vocational guidance, Psychological assessment, Psychological testing.
\end{abstract}

A avaliação psicológica é uma importante área de atuação profissional do psicólogo, sendo utilizada em muitos contextos, uma vez que as intervenções psicológicas devem ser amparadas por informações levantadas por instrumentos cientificamente estudados, com características psicométricas adequadas à situação e à população avaliada. Nesse sentido, o desenvolvimento de tecnologias de avaliação se faz urgente, levando-se em conta os novos avanços observados em países estrangeiros e as demandas próprias da população brasileira.

No que respeita ao campo da Orientação Profissional (OP), pode-se afirmar que ele é um dos que carecem de pesquisa e de mais instrumental de avaliação, para propiciar intervenções mais consistentes (Noronha, Freitas \& Ottati, 2003; Noronha \& Ambiel, 2006; Sparta, Bardagi \& Teixeira, 2006). No Brasil, a história mostra que no início e meados do Século XX a OP viveu um intenso desenvolvimento, com abertura de institutos e centros de pesquisa em psicologia aplicada à escolha e seleção profissonal, o que fez com que vários instrumentos e testes psicológicos, específicos para esse fim, fossem desenvolvidos e estudados. Entretanto, nas décadas de

\footnotetext{
${ }^{1}$ Endereço para correspondência:

ambielram@gmail.com / ana.noronha@saofrancisco.edu.br
}

Este trabalho contou com o apoio financeiro da Fundação de Amparo à Pesquisa do Estado de São Paulo (FAPESP).
1960 e 1970 os avanços que impulsionaram a área diminuíram, tendo sido retomados em meados da década de 1980, inclusive no que toca à construção de instrumentos (Noronha \& Ambiel, 2006; Noronha, Sisto \& Santos, 2007; Sparta, 2003).

Embora a partir da década de 1990, no Brasil, tenha havido maior interesse no que se refere aos instrumentos de avaliação psicológica voltados para a orientação profissional, tal como pontuado por Abade (2005) e Noronha e Ambiel (2006), os trabalhos de Noronha, Freitas e Ottati (2003) e Ottati, Noronha e Salviatti (2003) afirmaram que muitos dos instrumentos publicados no país não contavam com estudos sobre suas qualidades psicométricas, o que os tornava impróprios para uso profissional. Dos estudos que se dedicaram ao incremento dos testes, destaque pode ser dado aos de Melo-Silva e Santos (1998), que se dedicou à adaptação do Teste de Fotos de Profissões (BBT) para o Brasil; de Neiva (1999), que construiu a Escala de Maturidade para Escolha Profissional (EMEP); e de Primi, Moggi e Casellato (2004), que investigou as relações entre o Self-Directed Search (SDS) com o Inventário Fatorial de Personalidade (IFP).

Nesse sentido, observa-se que diversos construtos têm sido avaliados quando se trata de processos de orientação profissional, tais como os interesses profissionais, personalidade e habilidades (Noronha \& Ambiel, 2006). Especificamente no contexto estrangeiro, a autoeficácia também entra 
nesse rol (Bandura, 1977), aqui compreendida como o sistema de crenças que um sujeito tem a respeito da própria capacidade para planejar e executar cursos de ação específicos. Tais crenças apresentam relação direta com a seleção de metas, quantidade de esforço que se empreende para a consecução do objetivo, bem como a qualidade do desempenho do sujeito, tanto na execução da tarefa, quanto na confrontação dos obstáculos que se impõem (Bandura, 1997).

Hackett e Betz (1981) e Taylor e Betz (1983) iniciaram os estudos com a autoeficácia no domínio da escolha profissional, sugerindo uma relação importante entre as crenças de estudantes em suas habilidades educacionais e ocupacionais com as opções profissionais consideradas. A inserção do construto nesse domínio se deu a partir do desenvolvimento de uma escala padronizada que visava avaliar a confiança dos indivíduos para se engajar em tarefas de decisão profissional, a Career Decision-Making Self-Efficacy Scale (CDMSES, Escala de Autoeficácia para Tomada de Decisão de Carreira, em tradução livre dos autores deste artigo). É importante ressaltar, como vai ser descrito a seguir, que esta escala tem sido usada em todo o mundo, por meio de traduções e adaptações. Para fins de padronização de linguagem, o termo em inglês Career Decision Making Self-Efficacy será traduzido como Autoeficácia para Escolha Profissional.

Hackett e Betz (1981) e Taylor e Betz (1983) apoiaram-se na concepção de Crites $(1961 ; 1978)$ sobre a escolha profissional que, de um ponto de vista desenvolvimental, considerava que as pessoas poderiam variar em relação à maturidade para a decisão de carreira. Em seu modelo, Crites (1965, 1971) operacionaliza algumas variáveis importantes no processo de desenvolvimento e maturação de carreira, entre elas, as competências para escolha profissional, quais sejam, Correta autoavaliação, Coleta de informações ocupacionais, Seleção de objetivos, Planejamento de Futuro e Resolução de problemas (traduzido pelos presentes autores). Esta idéia é especialmente relevante para este trabalho, pois Hackett e Betz (1981) e Taylor e Betz (1983) se apoiaram em tais competências para desenvolver a CDMSES. Dessa forma, tomando por base os trabalhos de Crites (1965), Betz e Taylor (2001) e Álvarez-González (2008), as competências serão descritas sucintamente.

A primeira, denominada Correta Autoavaliação (Accurate self-appraisal), relaciona-se aos comportamentos de escolha de uma profissão de acordo com as próprias percepções de habilidades, interesses, valores, aspirações e crenças. A segunda competência, denominada Coleta de Informações Ocupacionais (Gathering occupational information), diz respeito ao conhecimento dos meios de busca de informação, bem como ao julgamento de importância acerca de quais informações serão úteis para se fazer uma escolha adequada.

A terceira competência é denominada Seleção de Objetivos (Goal selection) e é integrada por comportamentos capazes de selecionar uma profissão entre várias disponíveis, considerando as próprias expectativas com relação a essa seleção. A quarta é o Planejamento do Futuro (Future planning) e expressa-se por comportamentos de planejamento de ações práticas, visando aderir a uma certa profissão e, à médio prazo, satisfazer-se com a escolha feita. Por fim, a quinta a é Solução de Problemas (Problem solving), caracterizando-se por comportamentos indicativos da capacidade para reagir adaptativamente a situações em que ocorrem imprevistos relativos ao processo de escolha profissional. Assim, a primeira versão da CDMSES ficou composto por 50 itens, sendo 10 relativos a cada competência.

Entretanto, ao longo de mais de 20 anos de estudos do construto por meio dessa escala e de outras derivadas, em vários países, sua estrutura fatorial ainda é discutível. Alguns estudos suportando tal afirmação serão destacados a seguir.

A análise de Taylor e Betz (1983) revelou uma estrutura de quatro fatores pouco relacionada com a proposta original. Em outro estudo, Perterson e delMas (1998) encontraram resultados que sugeriram que a solução mais adequada seria a de dois fatores, a saber Coleta de Informações (Information gathering) e Tomada de Decisão (decision making). Em 2001, na África do Sul, Watson, Brand, Stead e Ellis realizaram uma Modelagem de Equação Estrutural para testar o modelo de cinco fatores da CDMSES, sendo que os dados não se mostraram adequados. Creed, Patton e Watson (2002) avaliaram a equivalência transcultural da estrutura da CDMSES, comparando os resultados de estudantes de uma escola australiana com uma sulafricana, chegando a soluções semelhantes com quatro fatores, quais sejam, Information Gathering (coleta de informações), Decision-making (tomada de decisão), Problem solving (resolução de problemas) e um quarto fator constituído em ambas as amostras por apenas dois itens, sendo considerado pouco confiável e sem interpretabilidade.

$\mathrm{Na}$ China, Hampton (2006) também encontrou quatro fatores, sendo o primeiro composto basicamente por itens das competências de autoavaliação e seleção de objetivos; o segundo por itens de planejamento; o terceiro, com itens de informações ocupacionais; e o quarto agrupou apenas três itens, sendo dois de resolução de problemas e um de planejamento. No México, Ramírez e Canto (2007) construíram e testaram uma escala baseada na CDMSES, tendo sido encontrados cinco fatores 
correspondentes às competências de Crites. $\mathrm{Na}$ Turquia, Işik (2010) utilizou a versão traduzida da CDMSES, considerando seus fatores teóricos.

Apesar das inconsistências apresentadas quanto à validade fatorial da CDMSES, de forma geral os estudos citados anteriormente indicam estimativas de precisão adequadas $(>0,70)$, sendo que outros demonstraram também sua utilidade prática. Por exemplo, Reese e Miller (2006) investigaram os efeitos de um curso de desenvolvimento de carreira na autoeficácia para escolha profissional de estudantes universitários indecisos. As atividades do curso eram desenvolvidas com o objetivo de implementar nos estudantes as cinco competências de Crites (1961), sendo que, nos resultados, pode-se observar um aumento significativo das médias na CDMSES em todos os fatores. Bollman (2009) delineou uma pesquisa semelhante à anterior, ou seja, com vistas a verificar os efeitos de um curso de exploração vocacional na autoeficácia para escolha profissional de graduandos indecisos, chegando a resultados semelhantes.

A discussão a respeito da teoria, estrutura fatorial e utilidade de instrumentos que avaliem a autoeficácia para escolha profissional é de importância essencial para este trabalho. Assim, mediante a problemática exposta na introdução, o presente estudo tem o objetivo de relatar o processo de construção dos itens da Escala de Autoeficácia para Escolha Profissional (EAE-EP).

\section{Etapa 1 - Construção de itens a partir da literatura}

Todo o processo de construção da EAE-EP foi respaldado pelo texto de Bandura (2006), em que é sugerido um guia para construção de escalas de autoeficácia. Portanto, o primeiro passo da construção dos itens contou com o levantamento da literatura a respeito do construto estudado, a partir de uma busca na base de dados eletrônica EBSCO, sem impor limite temporal, utilizando o termo "career decision-making selfefficacy". Foram localizados 193 resumos relacionados ao assunto e 34 artigos completos.

Como já foi discutido anteriormente na introdução, a leitura dos artigos e resumos encontrados indicaram que a autoeficácia para escolha profissional tem sido estudada em vários países do mundo por meio de diferentes versões da Career Decision-Making Self-Efficacy Scale (CDMSES, Taylor \& Betz, 1983). Observou-se também que há muita discussão a respeito da adequação da estrutura fatorial da escala ao modelo de Crites (1961), no qual foram baseadas as ações de construção dos itens da CDMSES. Assim, mesmo considerando a inconclusão dos achados até o presente a respeito da melhor forma de se avaliar o construto, optou-se neste estudo pela manutenção do mesmo referencial teórico e, baseando-se nas asserções de Crites (1961), foi iniciado o processo de construção dos itens a partir das leituras dos artigos encontrados e discussões dos mesmos realizadas pelo autores, em encontros semanais.

A tarefa de elaboração dos itens foi dividida de forma que a segunda autora atuou como juíza para a avaliação da pertinência teórica e clareza da redação. Foram elaboradas pelo primeiro autor 49 afirmativas, sendo dez alocadas na categoria "Correta Autoavaliação", 11 em "Coleta de informações ocupacionais", nove em "Seleção de objetivos", nove em "Planejamento de futuro" e dez em "Resolução de problemas".

A análise quanto à pertinência teórica dos itens aos pressupostos que conduziram sua elaboração indicou um nível de concordância de $83,6 \%$ ente os juízes, nível considerado adequado por Landis e Koch (1977), sendo que do total proposto, oito itens foram descartados por terem sido consensualmente considerados inadequados, restando 41. Quanto à pertinência dos itens às cinco categorias, apenas em um houve dúvida, sendo que ele estava alocado em "Seleção de objetivos" e passou a integrar a categoria "Coleta de informações ocupacionais". Assim, a configuração final após os descartes e alterações foi a seguinte: nove itens em "Correta Autoavaliação", 11 em "Coleta de informações ocupacionais", sete em "Seleção de objetivos", sete em "Planejar o futuro" e sete em "Resolução de problemas". Com relação à avaliação da clareza, nove itens mostraram-se com alguma inconsistência, seja de ordem gramatical ou de redação, que poderiam dificultar a compreensão e foram corrigidas.

Uma vez procedida essa etapa de construção dos itens iniciais, buscou-se levantar dados empíricos sobre a opinião das pessoas a respeito das habilidades necessárias para se fazer uma escolha profissional adequada e assim construir novos itens. Para tanto, realizou-se o estudo relatado a seguir.

Etapa 2 - Construção de itens a partir de dados empíricos

\section{Método}

\section{Participantes}

Participaram 149 pessoas, eleitas por conveniência, sendo $73,8 \%$ mulheres e $23,5 \%$ homens $(2,7 \%$ não deram essa informação), com idades variando entre 15 e 63 anos $(M=24,3 ; \mathrm{DP}=9,8)$. Quanto à escolaridade, a caracterização da amostra se configurou da seguinte forma: dois sujeitos $(1,3 \%)$ tinham ensino fundamental completo; 49 (32,9\%) estavam cursando o ensino médio em uma escola particular; $9(6 \%)$ tinham o ensino médio completo; 63 
(42,3\%) cursavam graduação em Psicologia em uma instituição de ensino superior particular; $14(9,4 \%)$ já tinham completado o ensino superior; seis $(4 \%)$ eram pós-graduados e; seis (4\%) não informaram. Ao lado disso, $55,7 \%$ dos sujeitos declararam estar trabalhando.

A variedade da amostra quanto à idade, escolaridade e situação ocupacional foi definida com vistas a abranger amplo espectro de conteúdos. Apesar do instrumento ser destinado à avaliação de estudantes do ensino médio, considerou-se importante coletar opiniões de pessoas que ainda não passaram pela situação de escolha e também dos que já passaram. Além disso, considerou-se que a opinião de pessoas que trabalham e que não trabalham poderia acrescentar informações importantes para a construção de itens.

\section{Instrumento}

O instrumento aplicado consistiu de duas partes. A primeira solicitava informações de identificação dos participantes, a saber, nome, sexo, idade, escolaridade e situação ocupacional atual (se trabalha ou não). A segunda era formada pela seguinte pergunta aberta: "Em sua opinião, o que uma pessoa precisa fazer para escolher bem uma profissão?”, com espaço de 18 linhas para a resposta.

\section{Procedimento}

Após a aprovação do presente projeto pelo Comitê de Ética em Pesquisa, iniciou-se a coleta de dados. Como se pretendeu abranger uma amostra diversificada em suas características de escolaridade e ocupação, a aplicação se deu em diferentes ambientes, sempre de forma coletiva. As aplicações ocorreram em salas de aula (universidade e ensino médio), em locais de trabalho (um salão de cabeleireiros e setor administrativo de uma universidade particular) e na rede de contatos pessoais dos pesquisadores. As aplicações duraram aproximadamente 15 minutos e todos os sujeitos maiores de idade assinaram o Termo de Consentimento Livre e Esclarecido (TCLE), enquanto os menores receberam autorização dos responsáveis.

\section{Resultados}

Com vistas a compreender os padrões de respostas dos participantes, foi realizada uma análise de conteúdo (Bardin, 1977) em relação às respostas ao instrumento. Assim, inicialmente todas as respostas foram lidas na íntegra pelos autores, sendo, em seguida, divididas em unidades de texto. Foram consideradas "unidades" fragmentos de texto que compunham as respostas dos sujeitos. $\mathrm{Na}$ Tabela 1 são apresentados três exemplos de respostas, com sua respectiva divisão em unidades, indicadas pelo sinal "/.

Tabela 1 - Exemplos de respostas e divisão por unidades

\begin{tabular}{llll}
\hline Sujeito & & & \\
\hline Sexo & Idade & Escolaridade & Profissão \\
\hline Feminino & 36 & Superior & Tutora de \\
& & Completo & relacionamento
\end{tabular}

Resposta

"A pessoa tem que ler muito, / fazer pesquisas na internet à respeito das profissões. / Tem também que tentar conversar com alguém que trabalhe diretamente na área escolhida para tirar as dúvidas. / Enfim, associar a teoria com a prática!/"

\begin{tabular}{llll}
\hline Feminino 24 & $\begin{array}{l}\text { Ensino médio } \\
\text { completo }\end{array}$ & $\begin{array}{l}\text { Auxiliar de } \\
\text { cabeleireira }\end{array}$
\end{tabular}

"Tem que saber o que deseja / e pensar sobre o que está disposto a perder ou ganhar, / precisa fazer um projeto de vida. / Mas, sempre de acordo com suas habilidades e interesses./"

$\begin{array}{llll}\text { Masculino } 17 & \begin{array}{l}\text { Cursando } \\ \text { ensino médio }\end{array} & \text { Estudante }\end{array}$

"A pessoa precisa se conhecer muito bem, / conhecer suas aptidões e dificuldades. / Precisa conhecer o curso de graduação, / mas também, precisa conhecer bem a profissão, / o campo de trabalho da mesma, / levar em consideração o mercado de trabalho. / Não pode ter medo de se arriscar./"

Assim, a divisão das respostas dos 149 sujeitos resultou em um total de 495 unidades, variando de uma a nove por pessoa, com média de 3,3 unidades. Em seguida, as unidades foram analisadas pelos autores e agrupadas, segundo sua semelhança semântica, em quatro categorias, sendo formuladas definições operacionais para cada uma, baseadas no conteúdo das unidades e em suas comunalidades (Tabela 2). É importante esclarecer que essas categorias foram formuladas unicamente a partir das 
respostas das pessoas e de acordo com os princípios técnicos da análise de conteúdo.

Tabela 2 - Categorias geradas a partir da análise de conteúdo, com as respectivas descrições

\begin{tabular}{ll}
\hline Categorias & Descrição \\
\hline Autoavaliação & Unidades que tratavam de assuntos e comportamentos relacionados a auto-conhecimento (de \\
& características pessoais, habilidades, personalidade, interesses, gostar da profissão ou curso, etc.); \\
& e/ou meios que proporcionem o auto-conhecimento (ajuda profissional, testes, orientação); \\
& e/ou autoavaliação acerca de suas condições físicas, emocionais e financeiras, envolvidas na \\
& execução do curso/profissão. Foco na pessoa. \\
& Exemplo de unidade: "procurar conhecer bem as habilidades que possui para uma melhor \\
& execução do trabalho"
\end{tabular}

Informação Unidades que indicavam comportamentos ou situações com a intenção de busca de

profissional conhecimento sobre cursos de formação profissional; e/ou de características das áreas e das profissões (rotina, salário, dentre outras) e mercado de trabalho, por meio de diferentes formas, como pesquisas, entrevistas, visitas, estágios, dentre outras. Foco no trabalho.

Exemplo de unidade: "ter um bom conhecimento das áreas escolhidas"

Maturidade e Unidades sobre comportamentos que poderiam servir de base para a escolha do curso ou engajamento profissão, levando-se em conta a independência (no sentido de ser uma escolha própria, autônoma, independente de outras pessoas ou fatores externos), responsabilidade sobre suas escolhas e empenho para se formar, trabalhar, e ter bom desempenho acadêmico e laboral. Busca por experiências antes mesmo da formação, como estágios, trabalhos voluntários, dentre outros. Foco no processo.

Exemplo de unidade: "estar preparado para enfrentar as dificuldades que virão pela frente"

Realização Unidades relativas a crenças sobre o retorno financeiro, na realização pessoal (prazer e satisfação na realização do curso/profissão), na realização profissional (estabilidade, permanência ou desistência da profissão, dentre outras) e no retorno para a sociedade. Foco nas conseqüências. Exemplo de unidade: "focar no que possa dar estrutura financeira e emocional"

Observa-se que estas categorias não estão diretamente relacionadas ao modelo de Crites (1961), embora tenham alguns pontos de convergência. As implicações teóricas e práticas dessa condição serão discutidas oportunamente.

A partir dessa categorização, foram selecionadas aleatoriamente 30 das 495 unidades, que foram submetidas à análise de seis juízes independentes, a fim de se avaliar a concordância quanto à classificação das categorias. Os juízes eram três estudantes de Psicologia, bolsistas de iniciação científica, uma mestranda, uma doutoranda e uma doutora em Psicologia, que participavam há um ano de grupo de estudos semanal sobre assuntos relacionados à orientação profissional. Em 22 unidades (73,3\%) houve concordância entre todos os juízes, indicando que a definição das categorias estava relativamente clara e coerente.

Para a análise final, duas pessoas que obtiveram o maior percentual de acertos $(86,4 \%)$ com relação às 30 unidades analisadas anteriormente, sendo uma graduanda e uma mestranda, foram recrutadas como juízas (J1 e J2) e, juntamente com os autores (A1 e A2), analisaram as unidades restantes, subtraindo-se as 30 que já haviam sido analisadas, totalizando 465 . Os níveis de concordância entre os juízes podem ser visualizados na Tabela 3.

Tabela 3 - Níveis de concordância quanto à classificação das 465 unidades

\begin{tabular}{llll}
\hline & A1 & A2 & J1 \\
\hline A2 & $93,3 \%$ & & \\
J1 & $76,3 \%$ & $74,9 \%$ & \\
J2 & $71,4 \%$ & $67,7 \%$ & $66,4 \%$ \\
\hline
\end{tabular}

Em seguida, foram selecionadas somente as unidades que obtiveram $100 \%$ de concordância de classificação entre os quatro juízes. Das 465 unidades analisadas, $259(55,7 \%)$ obtiveram tal índice, sendo dessas, 111 unidades $(42,8 \%)$ pertencentes à categoria
Autoavaliação; 98 unidades $(37,8 \%)$ à Informação profissional; $14(5,4 \%)$ à Maturidade e engajamento e 36 unidades $(13,9 \%)$ à Realização.

Com vistas a finalizar a versão inicial da escala, os autores analisaram qualitativamente as 259 unidades 
restantes, constatando que havia muitas com conteúdos semelhantes ou repetidos entre si e também em relação aos itens já construídos. Por exemplo, das 111 unidades classificadas como Autoavaliação, 31 $(28 \%)$ diziam respeito ao conhecimento das próprias habilidades. Outro exemplo pode ser dado em relação à categoria Realização, na qual, das 36 unidades aí classificadas, cinco (14\%) versavam sobre expectativas de retorno financeiro. Assim, as unidades com conteúdos semelhantes foram estudadas, agrupadas e geraram 27 itens. Portanto, a versão inicial da EAE-EP finalizou com um total de 68 itens.

Com relação à escolha do tipo de chave resposta, verificou-se na literatura estudos com escalas Likert de 11 pontos, como sugerido por Bandura (2006), 10, seis e cinco pontos, com características psicométricas favoráveis a todos. Entretanto, alguns estudos indicaram a equivalência ou mesmo o melhor desempenho de escalas de quatro pontos, tais como Garland (1991), Sangster, Willits, Saltiel, Lorenz e Rockwood (2001), Alexandre, Andrade, Vasconcelos, Araujo e Batista (2003) e Smith, Wakely, de Kruif e Swartz (2003). Dessa forma, optou-se por testar essa possibilidade na escala em construção.

O estímulo ao qual as pessoas deveriam responder aos itens foi "quanto você acredita na sua capacidade de:", seguindo-se os 68 itens. Por fim, seguindo-se a sugestão de Bandura (2006), foi incluída uma seção na escala para avaliar a intensidade da dificuldade para se fazer a decisão profissional percebida pelo respondente no momento da resposta, logo abaixo dos campos destinados à identificação, que incluíam nome, idade, sexo, escola, tipo de escola e série. Com sua versão inicial pronta, a EAE-EP foi submetida a uma aplicação piloto, conforme descrito a seguir.

Etapa 3 - Testagem piloto usando a versão inicial Escala de Autoeficácia para Escolha Profissional

O objetivo dessa etapa foi avaliar a clareza dos itens e das instruções por meio da aplicação da versão inicial da EAE-EP, construída anteriormente, em estudantes do Ensino Médio.

\section{Método}

\section{Participantes}

Participaram 22 estudantes do primeiro ano do Ensino Médio de uma escola particular do interior do estado de São Paulo, sendo 13 mulheres (59,1\%), oito homens $(36,4 \%)$ e um sujeito $(4,5 \%)$ que não indicou. As idades variaram entre 14 e 15 anos, sendo que a média ficou em 14,6 anos (DP=0,5).
Foi aplicada a versão inicial da Escala de Autoeficácia para Escolha Profissional, consistindo de 68 itens, em formato Likert de quatro pontos, avaliando quanto os sujeitos acreditam na própria capacidade de realizar as atividades descritas nos itens, variando de 1 - acredita pouco a 4 - acredita muito. A escala conta com uma segunda seção que avalia a dificuldade percebida pelo sujeito para escolher a profissão no momento da resposta ao instrumento e é constituída de apenas um item, também no formato Likert de quatro pontos, de muito fácil (1) a muito difícil (4). Alguns exemplos de itens da EAE-EP são "conhecer o dia-a-dia de uma profissão" e "convencer os outros de que sua escolha profissional é a mais certa para você".

\section{Procedimentos}

Após a assinatura do TCLE pelos responsáveis dos estudantes, a aplicação ocorreu na escola, em período de aula cedido exclusivamente para a aplicação e se deu de forma coletiva. Os instrumentos foram distribuídos aos sujeitos e a única consigna dada foi para que eles lessem as instruções, o exemplo e buscassem responder aos itens da forma que haviam entendido. Em caso de dúvida deveriam chamar o aplicador. Além disso, caso houvesse alguma dúvida quanto à linguagem utilizada, eles deveriam circular a palavra e anotar a dúvida no final da folha.

\section{Resultados}

Considerando que o objetivo principal dessa etapa era verificar a adequação das instruções e da linguagem empregada nos itens, os resultados que serão descritos a seguir são relativos às observações indicadas pelos sujeitos com relação ao que lhes foi solicitado. A principal observação feita nessa aplicação, realizada por seis estudantes $(27,3 \%$ do total), foi que a seção de avaliação da dificuldade em escolher uma profissão, na posição em que estava, confundia-se com as instruções para responder os itens da escala. Observou-se que as instruções das duas seções pareciam-lhes contraditórias, uma vez que na seção de avaliação da dificuldade o número 1 da escala Likert significava "muito fácil" e o número 4 "muito difícil", e já para a resposta aos itens o número 1 era "acredito pouco" e o 4 "acredito muito". Assim, buscando esclarecer essa situação optou-se por modificar a posição da seção, situando-a após os itens da Escala.

Além dessas, surgiram casualmente dúvidas referentes à grafia e aos significados de palavras e concordância das frases. Como não houve uma constância nessas dúvidas, cada uma foi analisada individualmente e os casos que realmente precisavam de ajuste, ou seja, que julgou-se como procedente a 
dúvida levantada, foram corrigidos e modificados na versão final da Escala. Um exemplo dessas dúvidas foi com relação à palavra "aptidão", que um dos estudantes não sabia o significado.

Vale ressaltar que em nenhum item houve dúvidas ou questionamentos acerca de sua estrutura como um todo, sendo que os problemas eram referentes a palavras ou expressões específicas. Assim, julgou-se que a exclusão de itens não seria necessária nesse momento, sendo que a e Escala permaneceu com 68 itens.

\section{Discussão}

Conforme explicitado na introdução, a tarefa de construir um instrumento de avaliação psicológica envolve diversas etapas e, especificamente nesse trabalho, buscou-se atender às recomendações de Bandura (2006). Vale destacar que não foi encontrada nenhuma publicação em português a respeito da autoeficácia no domínio específico da escolha profissional, o que impulsionou os autores a buscarem literatura estrangeira.

A partir do contato com o material, verificouse que o construto tem sido avaliado com base nas cinco competências sugeridas por Crites (1961), podese constatar também a escassez de material descritivo e empírico a respeito desse modelo teórico, uma vez que diversas buscas foram realizadas com pouco sucesso. Ainda assim, visando manter o referencial teórico, esforçou-se para se basear nessas competências para a formulação dos itens iniciais.

No segundo momento da pesquisa, outros itens foram construídos a partir de dados empíricos, que foram submetidos à análise de conteúdo. Essa análise gerou categorias que, por sua vez, foram avaliadas por juízes para verificar sua coerência e clareza. Como pôde-se perceber, duas categorias identificadas foram bastante próximas das competências de Crites (1961), quais sejam, Autoavaliação/Correta Autoavaliação e Informação Profissional/Coleta de Informações Ocupacionais. Com relação às outras duas categorias geradas, a saber, Maturidade e Engajamento, e Realização, não há uma clara ligação entre elas e as proposições do autor, que são Seleção de Objetivos, Planejamento de Futuro e Solução de Problemas, embora tenham, em diferentes aspectos, pontos em comum.

Pode-se verificar que as duas etapas de construção dos itens, descritas neste trabalho, podem levar a uma importante discussão teórica. Na primeira etapa, apesar de muitas pesquisas apontarem a fragilidade da utilização modelo de Crites (1961) como estrutura fatorial para a avaliação da autoeficácia para escolha profissional, a opção por manter tal referencial se deu por coerência com a literatura que deu origem ao estudo do construto. Entretanto, na estratégia utilizada na segunda etapa, procurou-se manter certa neutralidade a respeito desse referencial, buscando trabalhar a partir das respostas de pessoas de diferentes idades e situações ocupacionais e educacionais. Seguindo-se os pressupostos da análise de conteúdo, chegou-se a quatro categorias, avaliadas por juízes de forma independente e com nível aceitável de concordância, das quais duas podem ser relacionadas diretamente às competências de Crites, como já dito, enquanto que as outras duas mostraram-se apenas com pontos em comum.

Obviamente, o procedimento de análise de conteúdo, embora tenha um valor científico importante, não pode ser usado por si só para validar ou invalidar um modelo teórico, especialmente considerando as limitações da amostra deste estudo quanto ao seu tamanho e representatividade. Contudo, tal análise dá indícios de que na cultura do Brasil, a exemplo de outras nas quais a autoeficácia para escolha profissional também foi estudada (Watson, Brand, Stead \& Ellis, 2001; Creed, Patton \& Watson, 2002; Hampton, 2006; Işik, 2010), o modelo baseado nas cinco competências de Crites não seja empiricamente aplicável ou, de uma forma mais conservador, não seja tão adequado. Este estudo não tem a pretensão de fechar essa questão; ao contrário, é apenas um primeiro passo nesse sentido, já que, certamente, outros estudos serão levados a cabo e fomentarão tal discussão.

Nesse sentido, uma dificuldade que se encontrou neste trabalho foi de como integrar itens construídos de formas tão diferentes. Como foi mencionado ao longo dos resultados, os itens formulados na primeira etapa mostraram-se coerentes de acordo com a teoria que os embasou e bastante semelhantes a muitos que surgiram a partir das opiniões das pessoas, na etapa 2. Entretanto, a análise de conteúdo mostrou uma similaridade limitada com o modelo teórico. Dessa forma, com a opção da junção de todos os itens no mesmo instrumento, estudos futuros deverão determinar a retirada de alguns itens e a melhor definição fatorial para a escala.

Deve ser destacada uma diferença essencial entre a EAE-EP e instrumentos utilizados para avaliar a autoeficácia para escolha profissional em outros países. Nos estudos estrangeiros, são percebidas versões traduzidas e adaptadas da CDMSES, sendo que a EAE-EP, embora inevitavelmente baseada na mesma teoria, teve seus itens totalmente construídos no Brasil. É nesse sentido que a etapa 2 deste estudo ganha importância adicional: ao se coletar opiniões de pessoas brasileiras de características tão diversas entre si e construir itens baseando-se nessas respostas, 
buscou-se um modelo inspirado em publicações internacionais, mas com a linguagem e necessidades adequadas à população brasileira.

A respeito da estrutura da escala, fruto, das duas etapas iniciais, a quantidade de 68 itens construídos inicialmente pode ser considerada alta para esse tipo de escala, haja vista outros estudos já realizados com instrumentos compostos por 50 (Taylor \& Betz, 1983), 25 (Betz \& Taylor, 2001) e 16 itens (Peterson \& delMas, 1998). Entretanto, esse excesso foi intencional, na medida em que se supõe que mais alguns itens provavelmente devem ser excluídos em análises futuras.

Procurou-se seguir as sugestões de Bandura (2006) na formulação dos itens, principalmente no que toca à correspondência deles com o domínio de aplicação do construto e à análise de juízes sobre a adequação das afirmações. Assim, pode-se pensar que esse foi um primeiro esforço no sentido de se angariar evidências de validade baseadas no conteúdo semântico dos itens da EAE-EP.

Com relação à outra diretriz de Bandura (2006), qual seja, a utilização de escala Likert de 11 pontos, verifica-se que a decisão dos autores deste estudo não foi consoante a ela, optando-se por uma versão com quatro pontos. Essa decisão decorreu, em primeiro lugar, da falta de consenso a esse respeito na literatura sobre autoeficácia para escolha profissional, sendo que inicialmente a CDMSES contava com o formato de 11 pontos sugerido por Bandura (Taylor \& Betz, 1983), embora outros autores tenham encontrado evidências de validade para a versão com cinco pontos, tais como Creed e cols. (2002), Hampton (2006) e Page e cols. (2008). Além disso, estudos estatísticos que buscaram verificar a utilização de diferentes formatos de escala Likert em diversos contextos, tais como Garland (1991), Sangster e cols. (2001), Alexandre e cols. (2003) e Smith e cols. (2003) indicaram a possibilidade do uso dos quatro pontos. Entretanto, não se nega a possibilidade de que em estudos futuros sejam testados outros modelos de escala Likert ou a realização de análises de Rasch para verificar a adequação desse formato aos dados.

Por fim, na testagem piloto, que ocorreu com um número reduzido de participantes, o objetivo era submeter a escala a uma amostra que teria as características de usuários potenciais no futuro. Compreendendo que a aplicação da escala é sugerida para estudantes do Ensino Médio, optou-se por uma sala de $1^{\text {a }}$ série, entendendo que, se não houvesse dúvidas quanto a compreensão das instruções e dos itens com essa turma, a tendência também seria que aqueles com maior grau de escolaridade não teriam dificuldade.
De fato, os resultados demonstraram que não houve necessidade de mudanças significativas nos itens, sendo que a principal questão foi relativa à sua estrutura, o que implicou a mudança de localização da seção de avaliação da dificuldade. É interessante notar que, apesar de ser uma recomendação clara de Bandura (2006), em nenhum outro estudo que avalie o construto foi encontrada qualquer menção a essa seção.

\section{Considerações finais}

A construção de novos instrumentos de avaliação psicológica é uma necessidade urgente na realidade profissional da psicologia brasileira. Principalmente no que toca à área de $\mathrm{OP}$, essa necessidade é ainda mais clara, dada a escassez de instrumentos brasileiros válidos e precisos. Assim, com o presente trabalho, pretendeu-se contribuir em três frentes. A primeira é fornecer, a longo prazo, um instrumento válido e preciso para uso profissional de psicólogos brasileiros que trabalhem com orientação profissional e em outros âmbitos em que a problemática da escolha profissional se coloque para os adolescentes. Além disso, pretendeu-se também fornecer um modelo de construção de itens para instrumentos de avaliação psicológica, haja vista a constante necessidade de atualização e construção de novos instrumentos no Brasil. Adicionalmente, o presente trabalho pretendeu contribuir com a divulgação do construto autoeficácia no contexto nacional.

É importante ressaltar que a avaliação da Autoeficácia para escolha profissional pode ser de grande utilidade e importância em processos de OP, tanto grupais quanto individuais, principalmente no sentido de identificar necessidades e planejar intervenções. Assim, tal avaliação pode ser útil nos contextos escolar e clínico, auxiliando o profissional de psicologia a avaliar os programas oferecidos e implementar a qualidade dos atendimentos.

Sabendo da limitação de instrumentos disponíveis para uso diagnóstico no Brasil, a oferta de novos instrumentos pode se configurar como alternativa para que os psicólogos tenham seu trabalho substanciado por teorias empiricamente testadas $\mathrm{e}$ comprovadas. Nesse sentido, fomentar o estudo de construtos que ainda não são trabalhados de forma consistente na prática profissional e mesmo acadêmica, pode significar um ganho importante para as intervenções profissionais.

Assim, novas pesquisas devem ser procedidas com a Escala de Autoeficácia para Escolha Profissional, no sentido de clarificar e confirmar os resultados com amostras maiores e mais heterogêneas. 
Estudos visando explorar a estrutura fatorial, bem como avaliar suas relações com personalidade, dificuldades de decisão e interesses profissionais, poderão indicar caminhos interessantes para a melhoria do instrumento. Ainda, verificar sua potencialidade diagnóstica e para avaliação de programas e processos de orientação profissional podem contribuir como mais evidências de validade $\mathrm{e}$ para que a autoeficácia e toda teoria que a embasa seja mais difundida no Brasil.

\section{Referências}

Abade, F. L. (2005). Orientação Profissional no Brasil: Uma Revisão Histórica da Produção Científica. Revista Brasileira de Orientação Profissional, 6(1), 15 24

Alexandre, J. W. C., Andrade, D. F., Vasconcelos, A. P., Araujo, A. M. S., \& Batista, M. J. (2003). Análise do número de categorias da escala de Likert aplicada à gestão pela qualidade total através da teoria da resposta ao item. Trabalho apresentado no XXIII Encontro Nacional de Engenharia de Produção. Ouro Preto, MG, Brasil.

Álvarez-González, M. (2008). Career maturity: a priority for secundary education. Electronic Journal of Research in Educational Psychology, 16(3), 749-772.

Bandura, A. (1977). Self-efficacy: Toward a unifying theory of behavior change. Psychological Review, 84, 191- 215.

Bandura, A. (1997). Self-efficacy: The exercise of control. New York: W. H. Freeman and Company.

Bandura, A. (2006). Guide for constructing selfefficacy scales. Em F. Pajares \& T. Urdan (Orgs.), Selfeefficacy beliefs of adolescents. Greenwich, CT: Information Age Publishing.

Bardin, L. (1977). Análise de Conteúdo. Lisboa: Edições 70.

Betz, N. E., \& Taylor K. M. (2001). Manual for the Career Decision Self-efficacy Scale and CDMSE - Short Form. Manual técnico não publicado.

Bollman, L. M. (2009). An Examination of the Effect of a Career Exploration Course on the Career Decision Self-Efficacy of Traditional-age Undecided College Students. Tese de doutorado não publicada. Universidade de Toledo, EUA.

Creed, P. A., Patton, W., \& Watson, M. B. (2002). Cross-cultural equivalence of the career decisionmaking self-efficacy scale-short form: An Australian and south African comparison. Journal of career assessment, 10(3), 327-342.

Crites, J. O. (1961). A model for the measurement of vocational maturity. Journal of counseling psychology, 8 , 25-259.
Crites, J. O. (1965). Measurement of vocational maturity in adolescence: attitude test of the Vocational Develoment Inventory. Psychological Monografis, 79.

Crites, J. O. (1971). The maturity of vocational attitudes in adolescence. Washington, D.C.: American Personnel and Guidance Association, Inquiry Series Monograph, 2.

Crites, J. O. (1978). Theory and research handbook for the Career Maturity Inventory. Monterey, CA: CTB/McGraw-Hill.

Garland, R. (1991). The Mid-Point on a Rating Scale: Is it Desirable? Marketing Bulletin, 2, 66-70.

Hackett, G. \& Betz, N. E. (1981). A self-efficacy approach to the career development of women. Journal of Vocational Behavior, 18, 326-336.

Hampton, N. Z. (2006). A psychometric evaluation of the career decision self-efficacy scale-short form in Chinese high schools students. Journal of Career Development, 33(2), 142-155.

Işik, E. (2010). Career decision self-efficay among Turkish undergraduate students. Electronic Journal of Research in Educational Psychology, 8(2), 749-762.

Landis, J. R., \& Koch, G. G. (1977). The measurement of observer agreement for categorical data. Biometrics, 33, 159-174.

Melo-Silva, L. L., \& Santos, M. A. (1998). O BBT como instrumento diagnóstico em orientação profissional: uma abordagem psicodinâmica. Revista Brasileira de Orientacãa Profissional, 2(1), 5976.

Neiva, K. M. C. (1999). Escala de Maturidade para a Escolha Profissional (EMEP): Manual. São Paulo: Vetor Editora.

Noronha, A. P. P., \& Ambiel, R. A. M. (2006). Orientação profissional e vocacional: análise da produção científica. Psico-USF, 11(1), 75-84.

Noronha, A. P. P., Freitas, F. A., \& Ottati, F. (2003). Análise de instrumentos de avaliação de interesses profissionais. Psicologia Teoria e Pesquisa, 19 (3), 287-291.

Noronha, A. P. P., Sisto, F., \& Santos, A. A. A. (2007). Escala de Aconselhamento Profissional: Manual Técnico. Editora Vetor.

Ottati, F., Noronha, A. P. P., \& Salviati, M. (2003). Testes psicológicos: qualidade de instrumentos de interesse profissional. Interação, 7 (1).

Page, J., Bruch, M. A., \& Haase, R. F. (2008). Role of perfectionism and Five-Factor model traits in career indecision. Personality and Individual Differences, 45, 811-815.

Peterson, S. L., \& delMas, R. C. (1998). The component structure of Career Decision-making Self-efficacyfor underprepared college students. Journal of Career Development, 24(3), 209-225. 
Primi, R., Moggi, M. A., \& Caselatto, E. O. (2004). Estudo correlacional do inventário de busca autodirigida com o IFP. Psicologia Escolar e Educacional, 8(1), 47-54.

Ramírez, M. C., \& Canto, J. E. (2007). Development and evaluation of a scale for measuring selfefficacy in career choice in Mexican students. Electronic Journal of Research in Educational Psychology, 5(1), 37-56.

Reese, R. J., \& Miller, C. D. (2006). Effects of a University Career Development Course on Career Decision-Making Self-Efficacy. Journal of Career Assessment, 14(2), 252-266.

Sangster, R. L., Willits, F. K., Saltiel, J., Lorenz, F. O., \& Rockwood, T. H. (2001). The effects of numerical labels on response scales. Trabalho apresentado no Annual Meeting of the American Statistical Association. Acessado em 20 de Junho de 2008.

Smith Jr., E. V., Wakely, M. B., de Kruif, R. E. L. \& Swartz, C. W. (2003). Optimizing rating scales for self-efficacy (and other) research. Educational and psychological measurement, 63(3), 369-391.
Sparta, M. (2003). O desenvolvimento da orientação profissional no Brasil. Revista Brasileira de Orientação Profissional, 4(1/2), 1-11.

Sparta, M., Bardagi, M. P., \& Teixeira, M. A. P. (2006). Modelos e instrumentos de Avaliação em Orientação Profissional: perspectiva histórica e situação no Brasil. Revista Brasileira de Orientação Profissional, 7(2), 19-32.

Taylor, K. M., \& Betz, N. E. (1983). Applications of self-efficacy theory to the understanding and treatment of career indecision. Journal of Vocational Behavior, 22(1), 63-81.

Watson, M. B., Brand, H. J., Stead, G. B., \& Ellis, R. R (2001). Confirmatory factor analysis of the Career Decision-Making Self-efficacy Scale among south African university students. Journal of Industrial Psychology, 27(1), 43-46.

Recebido em fevereiro de 2010 Reformulado em maio de 2010 Aprovado em outubro de 2010

Sobre os autores:

Rodolfo Augusto Matteo Ambiel é Psicólogo, Mestre em Psicologia pelo Programa de Pós-graduação Stricto Sensu em Psicologia e Docente do curso de graduação em Psicologia da Universidade São Francisco. Membro do Departamento de Pesquisa e Produção de Testes da Editora Casa do Psicólogo.

Ana Paula Porto Noronha é Psicóloga, Doutora em Psicologia: Ciência e Profissão pela PUC de Campinas e Docente do Programa de Pós-graduação Stricto Sensu em Psicologia da Universidade São Francisco. 